\title{
Guest Editors' Introduction
}

\section{Consumer-Driven Health Care- Beyond Rhetoric with Research and Experience}

The search for ways to stem the rising tide of health insurance premiums and improve the value of care being purchased has entered a new era. Bolstered by the explosion of information technology and prompted by the managed care backlash, "consumer-driven" health care in a variety of changing forms has emerged as a possible solution. The promise of greater consumer control over their dollars, greater choice of providers, personalized decision support, and the potential to stem Americans' propensity for more care without anonymous parties assessing its costs and benefits has appeal to many. But fear of adverse risk selection and disproportionately greater out-of-pocket costs for those who are sicker or poorer draws equal opposition. With ideological differences running deep and with the stakes so high in all directions, it is not surprising that rhetoric and anecdote abound.

What do we mean by consumer-driven health care? Many would agree that the term generally refers to a health benefit design where consumers have a high deductible insurance plan, a personal account funded in various ways to pay for care, a gap between the annual amount put into the account, and an internet-based decision support system. But the names and labels differ, and with explicit legal and regulatory changes in 2002 and 2003 (the most recent of which is the Health Savings Account (HSA) provision of the Medicare Modernization Act (MMA)), the ways in which the plans are structured-and the corresponding incentives that accompany them-can vary a great deal, although the direction of change is shared. Because of this, we made the editorial decision not to ask authors in this issue to standardize their definitions and usages. Instead, you will read about slight variants of meanings and terms such as "consumer-driven health insurance," "defined contribution health plans," "medical savings accounts" (a type of plan authorized by HIPAA in 1996 that, like the new HSAs, has some very specific benefit design elements), and "consumer-centric health plans."

In health services research on market changes and new organizational arrangements and incentive systems, it is frequently necessary to conduct initial research that lumps organizations or plans (our area of interest in this case) into frameworks that ignore features or dimensions that may affect the 
outcomes of interest differently. Or, as we have in several articles in this issue, research into new areas may especially benefit from a case study approach, to examine in depth one particular plan. In either case, caution is necessary in generalizing the results to the rapidly evolving models in the field.

With health care issues prominent on the national agenda this year, the degree to which consumer-driven health care will work is of high interest to policymakers, employers and consumers alike. Fortunately, from our vantage point as sponsors of research to improve decision making with evidence, there is a growing thirst in the public and private sectors for solid evidence about the potentials and pitfalls of these new plans. This special issue of Health Services Research provides the first collection of research papers on the early experiences of consumer-driven health care along with invited commentaries designed to provide a range of perspectives from plans to policy and to the people affected. It is our hope that this collection will help expand the debate from one based largely on beliefs to one informed by evidence.

The idea for the special issue was born in early 2003 during an important collaboration between The Robert Wood Johnson Foundation's Changes in Health Care Financing and Organization (HCFO) program and The Commonwealth Fund. Just as HCFO had awarded a second major project on consumer-driven health care, the HCFO team (in particular, Anne Gauthier, co-Guest Editor of this issue and director of HCFO's program) was approached by Commonwealth grantees, Jon Gabel and Tom Rice, who were aware of additional work underway at the Kaiser Institute for Health Policy. The group of funders and researchers decided to join forces and resources to plan a conference to disseminate the research in a way that would effectively engage policymakers, purchasers, plans, providers, and researchers and policy analysts as active participants. The conference, held on September 15, 2003, was designed to present preliminary results (refined in the papers presented in this special issue) and bring the data to "real-life" situations by featuring reactions not from academics (that would occur in the paper peer review process), but from employers and health plans administrators and employee representatives who had experience with consumer-driven health care plans in action to hear their interpretations of the research in light of their experience. Policy implications were also important, and were considered by a stellar closing panel including policy scholars Karen Davis and Paul Ginsburg, union leader Gerry Shea, and employer/provider Robert Stevens.

While each study presented at the conference was fascinating on its own, the clichéd observation that the "whole is better than the sum of the parts" was clear to all involved-the collaborating sponsors, the researchers, and the 
editors-in-chief of HSR. The research summaries had the potential to be packaged into a very valuable special issue, but there were some hurdles particular to this topic that had to be overcome. Most important was the desire to not only have each paper be a scholarly publication, but to make the information available first and foremost to the purchaser audience and their consultants, who would need the data early enough in 2004 to make real decisions about their health care benefits for the next year. The aim of this special issue was to combine the merits of the peer review process with the advantages of relevance and timeliness of the information to inform "real-life" decisions.

This ambitious aim inspired a collective commitment among all involved to complete the editorial process within five months of the conference, an unusual and difficult pace. This commitment was bolstered by the dedication of Co-Editors-in-Chief Harold S. Luft and Ann Barry Flood to facilitating the use of research results by those who need them in a timely fashion. In addition to designing processes to foster shorter than usual review and revision times, they facilitated our being able to promote timely access via a web version of the final papers that was available prior to the printed version.

We then sought commentators, all with a keen interest in the results from a range of perspectives, ranging from purchaser to health plan to consumer advocate to policy observer. We were successful in attracting outstanding experts from the latter three roles, but perhaps not surprisingly, the employers we approached who had much to say at the conference or by phone were simply too occupied with their primary business to have time to write a commentary.

The special issue is divided into three major sections, with a concluding commentary. In the first section, the landscape of the early adopters is carefully profiled, covering the range of plan offerings and insights into which employers are choosing these plans-and why. Rosenthal and Milstein use national survey data of health plans to examine the prevalence of consumerdriven products and the degree to which the products sold embrace the concepts of consumerism. As expected, there were fewer enrollees in the models with personal care accounts (although they had grown substantially, primarily because mainstream managed care plans were entering rapidly into the consumer-directed market). While total enrollment comprised a small number of all insured workers, the trend was increasing. These data will provide an important baseline measure as the market continues to change. LoSasso, Rice, Gabel and Whitmore delve in depth into four firms' experiences. While their data are descriptive, the authors offer a rare clear window into risk selection 
issues (early favorable selection in these cases), the interactions between the employers and their employees as the plans were adopted, and the early limited use of the decision support tools (a finding consistent with Rosenthal and Milstein). Parente, Feldman, and Christianson investigate the characteristics of employees choosing consumer-driven health care in one large employer offering several health plan and product options. The results were surprising, particularly the fact that consumer-driven health plan enrollees were no younger or healthier than enrollees choosing the HMO option. They were, however, wealthier as was expected.

Commentaries by Scandlen, a policy analyst and known proponent of consumer-driven health care, and Halvorsen, the CEO of Kaiser Permanente, the nation's largest group model HMO, help interpret the findings. Of particular note, Scandlen emphasizes that consumer-driven health care is an innovation of the market, noting that characteristics of early adopters of an innovation differ in predictable ways from later adopters in a mature market, where sellers use the information from the earlier risk takers to change the product as lessons are learned. Halvorson focuses on the distribution of spending in the population and points out that because the vast majority of health care dollars are spent by a small portion of people, the incentives promoted by the existing models of consumer-driven health care (he focuses on MSAs) will be ineffective for the many healthy individuals in the population, will not promote consumer comparisons for the very sick, and may cause the chronically ill to avoid or postpone necessary care.

The second part of the issue concentrates on consumer experiences in their first year in consumer-driven health care. Christianson, Parente and Feldman survey enrollees of consumer-driven plans and more traditional plans in one large employer and compare their satisfaction along a variety of measures. Fowles, Kind, Braun, and Bertko provide a similar assessment in another employer, Humana, which developed consumer-driven health care options and offered them to its own employees before selling in the larger market. Both studies provide insights into features of the plans that were important to enrollees, who in general were a more sophisticated population (and healthier in the Fowles et al. case). They were satisfied with their overall experience and the plan information features, but these were not used to the degree anticipated by plan designers. Shearer, a consumer advocate, highlights the key findings of each paper, emphasizing that the plans have to date drawn only modest enrollment. She lays out a number of areas for further research for this phenomenon in their effects on the health care system that raise for her significant red flags. 
The third section of the issue provides evidence about health care utilization and expenditures in consumer-driven health plans compared with more traditional offerings. Tollen, Ross and Poor analyze employment, enrollment and claims data to assess the extent to which risk selection occurred in the Humana Plan also studied by Fowles et al. Their results were dependent on the data: using demographic data, the consumer-driven health plans did not experience favorable risk selection, but using claims data, favorable selection was pronounced. Parente, Feldman, and Christianson provide one of the first in-depth analyses of whether consumer-driven health care actually affects utilization and expenditures, looking at a single employer. They detail the effects across all types of services and spending and conclude (with careful caveats) that at least in the first year, expenditures were lower overall although higher in certain difficult-to-explain categories, such as hospitals. John Bertko, chief actuary for Humana, reviews the evidence in his commentary and observes that this early work offers the possibility for system-wide cost savings with little adverse effect on the average enrollee but concludes the "jury is still out" on the ultimate effects, and the imperative to continue the research is clear.

Karen Davis carefully reviews all of the evidence in this issue and provides four main conclusions from the body of evidence in this issue. She reaches, as we have, the conclusion that the products are too new to reach definitive determinations about their long-term value. She reviews the research underlying some of the premises of the model, and underscores the fact that the model in current forms is a blunt instrument and does not directly address root causes of higher costs. As a result, she posits that consumer-driven health care is not designed to improve health system performance or the quality, safety, and efficiency of care.

The evidence and commentaries in this special issue, while needing to be interpreted with caution, are rich with lessons to help purchasers, policymakers, plans, consumers and researchers as consumer-driven health care continues to evolve. At the moment, the reality of consumer-driven health care appears to be neither the panacea promoters would wish nor the poison opponents fear, and there are still concerns for how the poorer and sicker will fare. With favorable tax treatment offered under the HSA law that became effective January 1, 2004, and with subsequent favorable regulatory guidance issued through the first half of the year, more employers are likely to embrace this model.

Health services researchers have the opportunity to continue to provide evidence to allow a reasoned public debate as the market evolves. They can 
contribute to designing effective decision tools that provide good information about care and providers-not just their costs, but about quality, appropriateness and cost-effectiveness. They can continue to contribute to efforts to learn how best to align incentives facing providers so that mutual goals of value are reached, as this movement evolves. But this opportunity brings obligations as well-to understand the questions that decision makers are asking and to transfer knowledge in a timely and effective manner. While the evidence contained within this issue doesn't provide all the answers, it makes important strides toward a discussion based in fact rather than beliefs.

On a final note, two people contributed significantly to this issue in ways that were critical to its success. Jennifer Edwards, Senior Program Officer at the Commonwealth Fund, served as a key participant in designing the September conference and in conceptualizing this issue, and without her contributions, it would surely have a different shape. Bonnie Austin, Senior Manager at AcademyHealth in the HCFO program, helped to manage all aspects of the editorial process, including assisting the Co-Guest Editors in selecting reviewers and in soliciting commentaries. We appreciate their contributions.

Anne K. Gauthier Carolyn M. Clancy Guest Editors

Anne K. Gauthier is Vice President, AcademyHealth and Director, RWJF Changes in Health Care Financing and Organization (HCFO) program, she does not necessarily reflect the views of AcademyHealth or The Robert Wood Johnson Foundation. Carolyn M. Clancy, M.D., is Director of the Agency for Healthcare Research and Quality and Senior Associate Editor of $H S R$, she does not necessarily reflect official policy of AHRQ or the Department of Health and Human Services. 